\title{
Reaction between Atomic Oxygen and Bromomethanes Studied by Matrix Isolation Infrared Spectroscopy
}

\author{
Emilie Lasson and Claus J. Nielsen
}

Department of Chemistry, University of Oslo, PO Box 1033, Blindern, N-0315 Oslo, Norway

\begin{abstract}
Lasson, E. and Nielsen, C. J., 1997. Reaction between Atomic Oxygen and Bromomethanes Studied by Matrix Isolation Infrared Spectroscopy. - Acta Chem. Scand. 51: 1-7. (c) Acta Chemica Scandinavica 1997.

The reactions of $\mathrm{CH}_{3} \mathrm{Br}, \mathrm{CHBr}_{3}$, and $\mathrm{CBr}_{4}$ with atomic oxygen in argon matrices were studied by infrared spectroscopy. Both $\mathrm{O}\left({ }^{1} \mathrm{D}\right)$ and $\mathrm{O}\left({ }^{3} \mathrm{P}\right)$ was generated in situ by the UV photolysis of ozone. $\mathrm{O}\left({ }^{1} \mathrm{D}\right)$ reacted with $\mathrm{CH}_{3} \mathrm{Br}$ to give $\mathrm{H}_{2} \mathrm{CO}+\mathrm{HBr}$ or $\mathrm{CO}+\mathrm{H}_{2}+\mathrm{HBr}$, with $\mathrm{CBr}_{4}$ to give $\mathrm{COBr}_{2}+\mathrm{Br}_{2}$ or $\mathrm{CO}+2 \mathrm{Br}_{2}$, and with $\mathrm{CHBr}_{3}$ to give $\mathrm{HCOBr}+\mathrm{Br}_{2}, \mathrm{COBr}_{2}+\mathrm{HBr}$ or $\mathrm{CO}+\mathrm{HBr}+\mathrm{Br}_{2}$. Additional experiments were carried out with $\mathrm{CDBr}_{3}+\mathrm{O}$ and $\mathrm{CHBr}_{3}+{ }^{18} \mathrm{O}$. The analogue reactions with $\mathrm{O}\left({ }^{3} \mathbf{P}\right)$ resulted in only the carbonyl intermediates. All the carbonyl compounds decomposed upon prolonged photolysis resulting in $\mathrm{HBr}$ and $\mathrm{CO}$ as final products in the matrix. The initial step of the reactions is discussed, and an overall reaction pathway is proposed.
\end{abstract}

The environmental problems connected with the release of man made halocarbons into the atmosphere was recognised in the early seventies, when the inertness of CFCs (chlorofluorocarbons) to tropospheric breakdown was discovered. ${ }^{1}$ The fact that the CFCs could reach the stratosphere, where they photolysed, releasing active chlorine atoms, instigated extensive investigations of the atmospheric chemistry involving chlorine. ${ }^{2}$ The acknowledgement of bromine's ozone destruction potential came soon after, ${ }^{3}$ but because of the much smaller abundance its atmospheric impact did not initially receive the same amount of attention. Although much less bromine is released into the atmosphere, it is extremely important in the ozone destruction due to (1) the bromine chlorine synergism, ${ }^{4}$ (2) the instability of bromine reservoir species, and (3) the weakness of the $\mathrm{C}-\mathrm{Br}$ bond facilitating photolysis at lower altitudes in the stratosphere where ozone is most abundant and where a fractional destruction implicates a maximum ozone loss.

The destruction of halocarbons in the atmosphere has several pathways. The major breakdown process in the troposphere involves reaction with the $\mathrm{OH}$ radical. In the stratosphere direct photolysis is another possibility and reaction with atomic oxygen a third. Only a few spectroscopic studies of products from oxygen atom reactions with halocarbons have so far been presented, ${ }^{5-9}$ among these is a comparative study of $\mathrm{CH}_{2} \mathrm{Cl}_{2}$ and $\mathrm{CH}_{2} \mathrm{Br}_{2}$ reactions. ${ }^{9}$ In the following we present our results from similar product studies of the reactions between $\mathrm{O}\left({ }^{1} \mathrm{D}\right)$ and $\mathrm{O}\left({ }^{3} \mathrm{P}\right)$ and $\mathrm{CH}_{3} \mathrm{Br}, \mathrm{CHBr}_{3}$ and $\mathrm{CBr}_{4}$ in argon matrices. Preliminary results from this study have been published earlier. ${ }^{10}$

\section{Experimental}

The experiments were carried out by co-depositing mixtures of the $\mathrm{CH}_{x} \mathrm{Br}_{y} / \mathrm{Ar}(1: 500)$ and $\mathrm{O}_{3} / \mathrm{Ar}(1: 200)$ through a dual-nozzle system onto the cold window of an Air Products 202A Displex unit at $15 \mathrm{~K}$. Infrared spectra were obtained in the $4000-500 \mathrm{~cm}^{-1}$ region at $1 \mathrm{~cm}^{-1}$ resolution using a Bruker IFS 88 Fourier transform spectrometer. Dual nozzle deposition was employed in order to avoid surface induced reactions between the halocarbons and ozone. The atomic oxygen was generated in situ by photolysis of the ozone using filtered UV light from a medium pressure mercury lamp. A $280 \mathrm{~nm}$ cut-off filter results in $\mathrm{O}\left({ }^{1} \mathrm{D}\right)$ as well as $\mathrm{O}\left({ }^{3} \mathrm{P}\right)$ production from the ozone photolysis, a $320 \mathrm{~nm}$ cut-off filter results in only $\mathrm{O}\left({ }^{3} \mathrm{P}\right) .{ }^{11}$ The halocarbons did not show any sign of photodecomposition upon exposure to wavelengths longer than $280 \mathrm{~nm}$. Ozone was generated from highgrade oxygen by electrical discharge in a closed system and trapped in liquid nitrogen. The $\mathrm{CH}_{3} \mathrm{Br}, \mathrm{CHBr}_{3}$ and $\mathrm{CBr}_{4}$ were standard p.a. laboratory reagents that were checked for impurities by GC-MS before use. Deuterated bromoform and ${ }^{18} \mathrm{O}_{2}$ originated from Eurisotop.

\section{Results}

Parent compounds. Our infrared spectra of matrix isolated ozone are in good agreement with literature data, ${ }^{12,13}$ but they invariably show traces of both $\mathrm{CO}$ and $\mathrm{F}_{2} \mathrm{CO}$ originating from the vacuum line discharge synthesis of ozone. The infrared bands of $\mathrm{CH}_{3} \mathrm{Br}$ are listed in the Table 1 and compared with previous results of the vapour $^{14}$ and of matrix isolation. ${ }^{15}$ The similar data for 
Table 1. Infrared spectral data (in $\mathrm{cm}^{-1}$ ) for $\mathrm{CH}_{3} \mathrm{Br}$.

\begin{tabular}{llll}
\hline \multirow{3}{*}{$\begin{array}{l}\text { Vapour } \\
\text { Ref. 17 }\end{array}$} & \multicolumn{2}{l}{ Argon matrix } & \\
\cline { 2 - 3 } & Ref. 18 & This work & Interpretation \\
\hline 3056.6 & 3054.5 & $3055(\mathrm{~m})$ & $v_{4}$ \\
& $2977.9(\mathrm{~m})^{a}$ & $2977(\mathrm{w}-\mathrm{m})$ & $v_{3}+v_{4}+v_{6}$ \\
2973 & $2967.4(\mathrm{~s})$ & $2966(\mathrm{~s})$ & $v_{1}$ \\
2862.0 & $2850.6(\mathrm{~m})$ & $2850(\mathrm{w})$ & $2 v_{5}$ \\
1442.7 & $1436.0(\mathrm{~s})$ & $1437(\mathrm{~s})$ & $v_{5}$ \\
1305.9 & $1300.4(\mathrm{~s})$ & $1300(\mathrm{~s})$ & $v_{2}$ \\
954.4 & $952.8(\mathrm{~s})$ & $952(\mathrm{~s})$ & $v_{6}$ \\
610.5 & & $603(\mathrm{w})$ & $v_{3}$ \\
\hline
\end{tabular}

${ }^{a}$ Abbreviations: s, strong; m, medium; w, weak.

$\mathrm{CHBr}_{3}$ and $\mathrm{CDBr}_{3}$ are given in Tables 2 and 3, respectively, together with those of the gas phase ${ }^{16}$ and earlier matrix isolation work. ${ }^{17}$ To our knowledge $\mathrm{CDBr}_{3}$ has not been studied by matrix isolation before. With the exceptions of $v_{3}$ and $v_{6}$, falling outside the range of our experimental set-up, the remaining fundamental modes have been observed. The infrared bands of $\mathrm{CBr}_{4}$ are shown in Table 4 and are compared with data from the liquid $^{18}$ and with results from an earlier matrix isolation study. ${ }^{19}$ Photolysis of the parent matrix isolated bromine compounds did not result in observable decomposition products within the timescales used in our experiments.

Table 2. Infrared spectral data (in $\mathrm{cm}^{-1}$ ) for $\mathrm{CHBr}_{3}$.

\begin{tabular}{llll}
\hline & \multicolumn{2}{l}{ Argon matrix } & \\
\cline { 2 - 3 } $\begin{array}{l}\text { Vapour } \\
\text { Ref. 19 }\end{array}$ & Ref. 20 & This work & Interpretation \\
\hline $3049.8(\mathrm{~m})^{\mathrm{a}}$ & & $3063(\mathrm{~m})$ & $v_{1}$ \\
& & $1331(\mathrm{~m})$ & $2 v_{5}$ \\
$1148.6(\mathrm{vs})$ & 1153.5 & $1153(\mathrm{~s})$ & $v_{4}$ \\
& 1147.0 & $1146(\mathrm{~m})$ & \\
& & $695(\mathrm{w})$ & $v_{2}+v_{6}$ \\
$668.8(\mathrm{vs})$ & 667 & $667(\mathrm{~s})$ & $v_{5}$ \\
$542.6(\mathrm{w})$ & 664 & $644(\mathrm{~m})$ & \\
$223.2(\mathrm{vw})$ & 543.5 & $542(\mathrm{~m})$ & $v_{2}$ \\
155 & & & $v_{3}$ \\
& & & $v_{6}$ \\
\hline
\end{tabular}

${ }^{a}$ Abbreviations: s, strong; m, medium; w, weak.

Table 3. Infrared spectral data (in $\mathrm{cm}^{-1}$ ) for $\mathrm{CDBr}_{3}$.

\begin{tabular}{lll}
\hline $\begin{array}{l}\text { Vapour } \\
\text { Ref. 19 }\end{array}$ & Argon matrix & Interpretation \\
\hline $2272.5(\mathrm{~m})^{a}$ & $2281(\mathrm{~m})$ & $v_{1}$ \\
& $1286(\mathrm{~m})$ & $2 v_{5}$ \\
& $1166(\mathrm{~m})$ & $v_{2}+v_{5}$ \\
$851.5(\mathrm{vs})$ & $869(\mathrm{~s})$ & $v_{4}$ \\
& $851(\mathrm{~s})$ & \\
$645.2(\mathrm{vs})$ & $645(\mathrm{vs})$ & $v_{5}$ \\
$524.1(\mathrm{w})$ & $627(\mathrm{~m})$ & \\
222.3 & $524(\mathrm{w})$ & $v_{2}$ \\
155.1 & & $v_{3}$ \\
& & $v_{6}$ \\
\hline
\end{tabular}

${ }^{a}$ Abbreviations: s, strong; m, medium; w, weak.
Table 4. Infrared spectral data (in $\mathrm{cm}^{-1}$ ) for $\mathrm{CBr}_{4}$.

\begin{tabular}{llll}
\hline & \multicolumn{2}{l}{ Argon matrix } \\
Liquid \\
\cline { 2 - 3 } Ref. 21 & Ref. 22 & This work & Interpretation \\
\hline & & $1345(\mathrm{w})^{a}$ & $2 v_{3}$ \\
671 & 675 & $675(\mathrm{~s})$ & $v_{3}$ \\
267 & & $v_{1}$ \\
182 & & & $v_{4}$ \\
122 & & & $v_{2}$ \\
\hline
\end{tabular}

${ }^{a}$ Abbreviations: s, strong; m, medium; w, weak.

Photolysis of $\mathrm{CH}_{3} \mathrm{Br} / \mathrm{O}_{3}$. The matrix spectra of co-deposited $\mathrm{CH}_{3} \mathrm{Br}$ and $\mathrm{O}_{3}$ in argon revealed no additional bands. Annealing the matrix to $35 \mathrm{~K}$ for $30 \mathrm{~min}$ showed no new features in the spectrum, thus indicating that if any complexation is taking place it is too weak to induce an observable pertubation of the parent bands.

After $15-20 \mathrm{~min}$ of irradiation $(\lambda>280 \mathrm{~nm})$ several new features appeared in the characteristic spectral regions of carbonyls, $\mathrm{CO}$ and $\mathrm{HBr}$ (Table 5). Prolonged irradiation resulted in an increase of the band intensities in the $\mathrm{CO}$ and $\mathrm{HBr}$ regions and a corresponding decrease in the other bands. Growth curves showed that there were two reaction channels: one leading to a carbonyl compound and another leading direct to $\mathrm{CO}$ and $\mathrm{HBr}$. Further, the carbonyl product was very stable towards photolysis. After $28 \mathrm{~h}$ of UV irradiation the $1728 \mathrm{~cm}^{-1}$ band showed a slight decrease, and it was still present after 46 hours of irradiation. Annealing at $35 \mathrm{~K}$ for $30 \mathrm{~min}$ resulted in small spectral changes. Exerts of the IR spectra are shown in Fig. 1.

When UV light with $\lambda>320 \mathrm{~nm}$ was used for generating $\mathrm{O}\left({ }^{3} \mathrm{P}\right)$ very small spectral changes appeared. After several hours of irradiation, weak traces of the 2886, 2819, 1728, 1495, 1247 and $1173 \mathrm{~cm}^{-1}$ bands were observed.

Photolysis of $\mathrm{CHBr}_{3} / \mathrm{O}_{3}$. The spectrum of co-deposited $\mathrm{CHBr}_{3}$ and $\mathrm{O}_{3}$ in argon showed no additional bands that could be attributed to any strong complex formation as for the methylbromide. After irradiation $(\lambda>280 \mathrm{~nm})$

Table 5. Product bands (in $\mathrm{cm}^{-1}$ ) from the $\mathrm{CH}_{3} \mathrm{Br}+\mathrm{O}\left({ }^{1} \mathrm{D}\right)$ experiment.

\begin{tabular}{ll}
\hline $\mathrm{CH}_{3} \mathrm{Br} /{ }^{16} \mathrm{O}_{3}$ & \\
\cline { 1 - 1 } Vib. freq. & Assignment \\
\hline $2886(w)^{a}$ & $v(\mathrm{CH})$ in $\mathrm{H}_{2} \mathrm{CO} \cdots \mathrm{HBr}$ \\
$2819(w)$ & $v(\mathrm{CH})$ in $\mathrm{H}_{2} \mathrm{CO} \cdots \mathrm{HBr}$ \\
$2520(\mathrm{~m})$ & $v(\mathrm{HBr})$ in $\mathrm{OC} \cdots \mathrm{HBr}$ \\
$2340(w)$ & $v(\mathrm{HBr})$ in $\mathrm{H}_{2} \mathrm{CO} \cdots \mathrm{HBr}$ \\
$2152(\mathrm{~s})$ & $v(\mathrm{CO})$ in $\mathrm{OC}^{2} \cdot \mathrm{HBr}$ \\
$1728(\mathrm{~s})$ & $v(\mathrm{C}=\mathrm{O})$ in $\mathrm{H}_{2} \mathrm{CO} \cdots \mathrm{HBr}$ \\
$1495(w)$ & $\delta(\mathrm{CH})$ in $\mathrm{H}_{2} \mathrm{CO} \cdots \mathrm{HBr}$ \\
$1247(w)$ & $\delta(\mathrm{CH})$ in $\mathrm{H}_{2} \mathrm{CO} \cdots \mathrm{HBr}$ \\
$1173(w)$ & $\delta(\mathrm{CH})$ in $\mathrm{H}_{2} \mathrm{CO} \cdots \mathrm{HBr}$ \\
\hline
\end{tabular}

a Abbreviations: s, strong; m, medium; w, weak. 

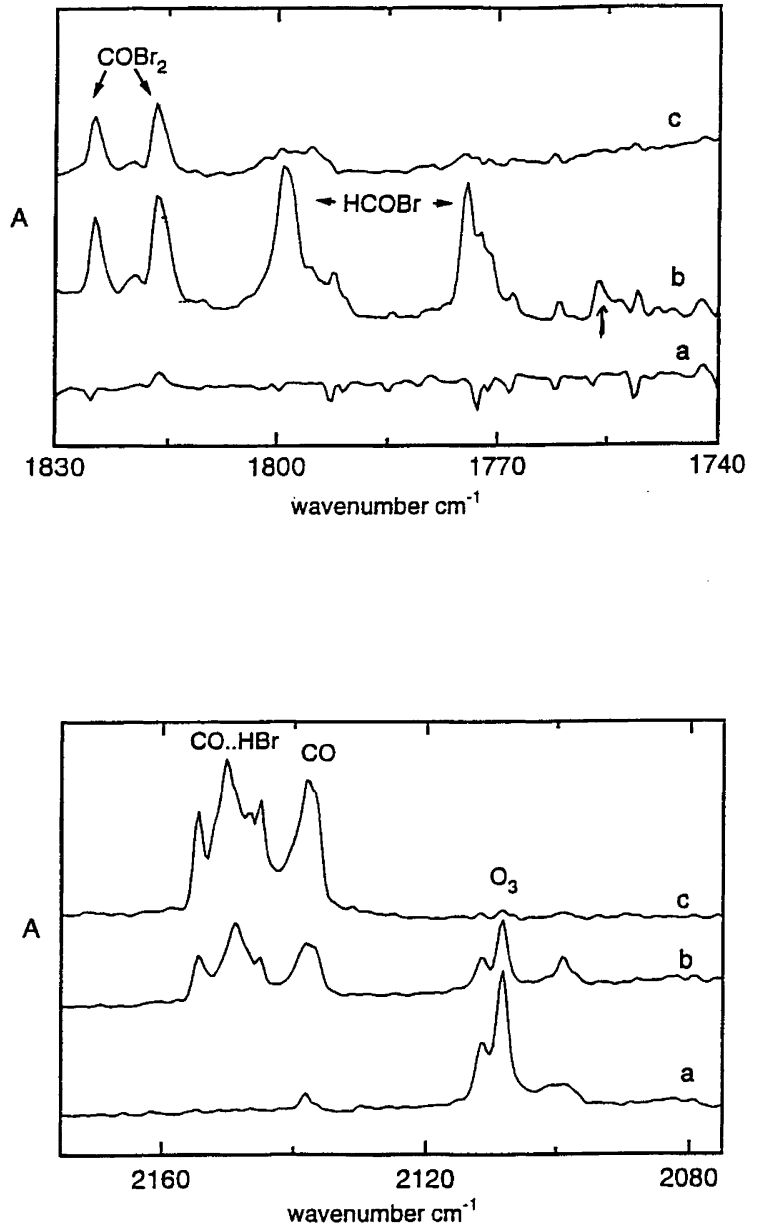

Fig. 1. Upper: The carbonyl stretching region for $\mathrm{CHBr}_{3} / \mathrm{O}_{3}$ in an argon matrix. (a) After deposition, (b) after $1 \mathrm{~h}$ of UV irradiation filtered at $280 \mathrm{~nm}$, (c) after $15 \mathrm{~h}$ of UV irradiation filtered at $280 \mathrm{~nm}$. Lower: The $\mathrm{CO}$ and $\mathrm{O}_{3}$ vibrational regions for $\mathrm{CHBr}_{3} / \mathrm{O}_{3}$ in an argon matrix. (a) After deposition, (b) after $1 \mathrm{~h}$ of UV irradiation filtered at $280 \mathrm{~nm}$, (c) after $31 \mathrm{~h}$ of UV irradiation filtered at $280 \mathrm{~nm}$.

the spectrum revealed several new bands: Tables 6 and 7 summarise the results from experiments with $\mathrm{CHBr}_{3} / \mathrm{O}_{3}$, $\mathrm{CDBr}_{3} / \mathrm{O}_{3}$ and $\mathrm{CHBr}_{3} /{ }^{18} \mathrm{O}_{3}$. Bands which disappeared upon prolonged photolysis are collected in Table 6, while bands increasing throughout the experiment are listed in Table 7. Exerts of the IR spectra are shown in Fig. 2. Some of the experiments showed traces of the $1816 \mathrm{~cm}^{-1}$ band (attributed to $\mathrm{COBr}_{2}$, vide infra) after deposition. Mass spectrometry of the staring sample showed no impurities and $\mathrm{COBr}_{2}$ is probably formed in the reservoir bulb during deposition. Experiments with a $320 \mathrm{~nm}$ cutoff filter giving only $\mathrm{O}\left({ }^{3} \mathrm{P}\right)$ resulted in negligible reaction: no bands in the $\mathrm{HBr}$ or $\mathrm{CO}$ region, and only traces of the carbonyl region bands were observed.

Growth curves of the primary product bands are shown in Figs. 3a-3c. As can be seen, the $1825 \mathrm{~cm}^{-1}$ band correlate with the $744 \mathrm{~cm}^{-1}$ band (Fig. 3a), the 1816 with the $737 \mathrm{~cm}^{-1}$ band (Fig. 3b), and the 1799 and 1774 and $1755 \mathrm{~cm}^{-1}$ bands have very similar time profiles (Fig. 3c) that differ significantly from those of the $1825 / 744$ and $1816 / 737 \mathrm{~cm}^{-1}$ pairs. Growth curves for the bands in the $\mathrm{CO}$ and $\mathrm{HBr}$ regions of the spectrum (not given) reveal that there is a direct channel as well as an indirect (photolytic) channel to these compounds.

Photolysis of $\mathrm{CBr}_{4} / \mathrm{O}_{3}$. The co-deposited $\mathrm{CBr}_{4}$ and $\mathrm{O}_{3}$ sample revealed no bands other than those of the parent molecules. Irradiation of the mixture only resulted in a few new features. In the carbonyl region bands appeared at 1822 and at $1816 \mathrm{~cm}^{-1}$. In the $\mathrm{CO}$ region a new band grew up at $2147 \mathrm{~cm}^{-1}$ in addition to the free $\mathrm{CO}$ band at $2138 \mathrm{~cm}^{-1}$ present from the beginning. Annealing the photolyzed matrix at $30 \mathrm{~K}$ increased the intensity of the $1822 \mathrm{~cm}^{-1}$ band somewhat and certainly gave a substantial increase in the $2147 \mathrm{~cm}^{-1}$ band. Experiments carried out with the $320 \mathrm{~nm}$ filtered ligh source giving $\mathrm{O}\left({ }^{3} \mathrm{P}\right)$ show the same carbonyl bands, but the $2147 \mathrm{~cm}^{-1}$ band does not appear.

\section{Discussion}

The lifetime of $O\left({ }^{1} \mathrm{D}\right)$ is ca. $150 \mathrm{~s}$ in the gas phase, ${ }^{20} 32 \mathrm{~s}$ in a neon matrix ${ }^{21}$ and $0.78 \mathrm{~s}$ in a $\mathrm{SF}_{6}$ matrix. ${ }^{22} \mathrm{~A}$ recent study of the photochemistry of ozone in argon matrices suggests that once an $\mathrm{O}\left({ }^{1} \mathrm{D}\right)$ atom escapes the matrix cage where it is generated, it moves easily through the argon lattice because of the short-range attractive inter-

Table 6. Intermediate product bands (in $\mathrm{cm}^{-1}$ ) from the $\mathrm{CHBr}_{3}+\mathrm{O}\left({ }^{1} \mathrm{D}\right.$ ) experiments.

\begin{tabular}{|c|c|c|c|}
\hline \multirow{2}{*}{$\frac{\mathrm{CHBr}_{3} /{ }^{16} \mathrm{O}_{3}}{\text { Vib. freq. }}$} & \multirow{2}{*}{$\frac{\mathrm{CHBr}_{3} /{ }^{18} \mathrm{O}_{3}}{\text { Vib. freq. }}$} & \multicolumn{2}{|l|}{$\mathrm{CDBr}_{3} /{ }^{16} \mathrm{O}_{3}$} \\
\hline & & Vib. freq. & Assignment \\
\hline $1825(\mathrm{~m})^{a}$ & $1783(\mathrm{~m})$ & $1826(\mathrm{~m})$ & $v(C=O)$ in $\mathrm{COBr}_{2} \cdots \mathrm{HBr}$ \\
\hline $1816(\mathrm{~m})$ & $1775(\mathrm{~m})$ & $1816(\mathrm{~m})$ & $v(C=O)$ in $\mathrm{COBr}_{2}$ \\
\hline $1799(\mathrm{sm})$ & $1742(\mathrm{~m})$ & $1745(\mathrm{~m})$ & $v(C=O)$ in $\mathrm{HCOBr}$ \\
\hline $1774(\mathrm{sm})$ & $1737(\mathrm{~m})$ & $1739(\mathrm{~m})$ & $v(C=O)$ in $\mathrm{HCOBr} \cdots \mathrm{Br}_{2}$ \\
\hline $1756(w)$ & $1716(w)$ & $1724 / 21(w)$ & $v(\mathrm{C}=\mathrm{O})$ in $\mathrm{HCOBr} \cdots \mathrm{HBr}$ \\
\hline & $773(\mathrm{mw})$ & & $v(\mathrm{C}-\mathrm{Br})$ in $\mathrm{COBr}_{2} \cdots \mathrm{HBr}$ \\
\hline & $766(\mathrm{mw})$ & & $v(\mathrm{C}-\mathrm{Br})$ in $\mathrm{COBr}_{2}$ \\
\hline $745(\mathrm{~m})$ & $737(\mathrm{~m})$ & $745(\mathrm{~m})$ & $v(\mathrm{C}-\mathrm{Br})$ in $\mathrm{COBr} \ldots \mathrm{HBr}$ \\
\hline $738(\mathrm{~m})$ & $729(\mathrm{~m})$ & $738(\mathrm{~m})$ & $v(\mathrm{C}-\mathrm{Br})$ in $\mathrm{COBr}_{2}$ \\
\hline
\end{tabular}

abbreviations: s, strong; m, medium; w, weak. 
Table 7. Final product bands (in $\mathrm{cm}^{-1}$ ) from the $\mathrm{CHBr}_{3}+\mathrm{O}\left({ }^{1} \mathrm{D}\right.$ ) experiments.

\begin{tabular}{llll}
\hline $\mathrm{CHBr}_{3} /{ }^{16} \mathrm{O}_{3}$ & $\mathrm{CHBr}_{3} /{ }^{18} \mathrm{O}_{3}$ & & $\mathrm{CDBr}_{3} /{ }^{16} \mathrm{O}_{3}$ \\
\cline { 2 - 3 } Vib. freq. & Vib. freq. & Vib. freq. & Assignment \\
\hline $2518(\mathrm{~m})^{a}$ & $2518(\mathrm{~m})$ & $1808(\mathrm{~m})$ & $v(\mathrm{HBr})$ in $\mathrm{HBr} \cdots \mathrm{CO}$ \\
$2515(\mathrm{~m})$ & $2515(\mathrm{~m})$ & $1806(\mathrm{~m})$ & \\
$2510(\mathrm{w})$ & $2510(\mathrm{w})$ & $1804(\mathrm{w})$ & \\
$2507(\mathrm{w})$ & $2507(\mathrm{w})$ & $1800(\mathrm{w})$ & \\
$2502(\mathrm{w})$ & $2502(\mathrm{w})$ & $1797(\mathrm{~m})$ & $v(\mathrm{HBr})$ in $(\mathrm{HBr})_{2} \cdots \mathrm{CO}$ \\
$2498(\mathrm{~m})$ & $2498(\mathrm{~m})$ & $1795(\mathrm{w})$ & $v(\mathrm{HBr})$ in $(\mathrm{HBr})_{2} \cdots \mathrm{CO}$ \\
$2488(\mathrm{w})$ & $2488(\mathrm{w})$ & $2155(\mathrm{~m})$ & $v(\mathrm{CO})$ in $\mathrm{CO} \cdots(\mathrm{HBr})_{2} / \mathrm{CO} \cdots \mathrm{HBr}$ \\
$2154(\mathrm{sm})$ & $2103(\mathrm{~m})$ & $2150(\mathrm{w})$ & \\
$2150(\mathrm{w})$ & & $2146(\mathrm{~m})$ & $v(\mathrm{CO})$ in $\mathrm{CO} \cdots \mathrm{Br}_{2}$ \\
$2149(\mathrm{w})$ & & $2138(\mathrm{sm})$ & $v(\mathrm{CO}) \mathrm{CO}$ \\
$2147(\mathrm{~m})$ & $2097(\mathrm{~m})$ & & \\
$2145(\mathrm{w})$ & $2087(\mathrm{~m})$ & & \\
$2138(\mathrm{sm})$ & & &
\end{tabular}

${ }^{a}$ Abbreviations: s, strong; m, medium; w, weak.
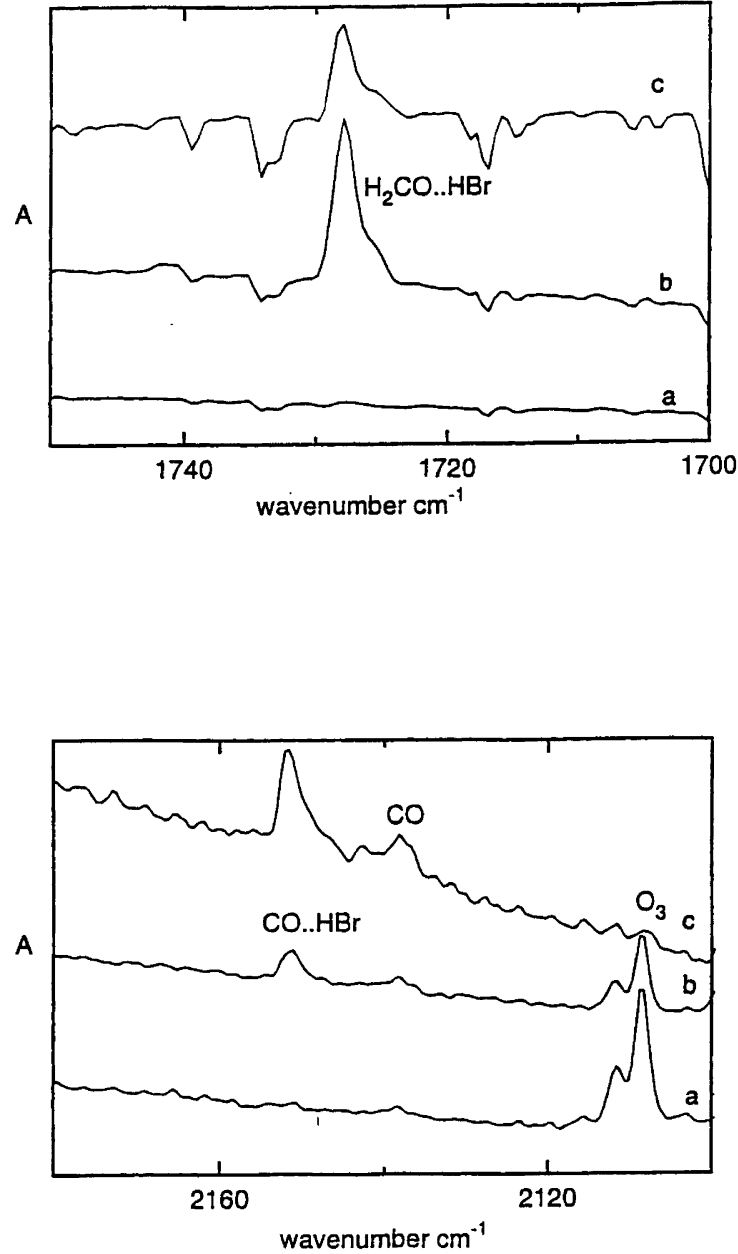

Fig. 2. Upper: The carbonyl stretching region for $\mathrm{CH}_{3} \mathrm{Br} / \mathrm{O}_{3}$ in an argon matrix. (a) After deposition, (b) after $1 \mathrm{~h}$ of UV irradiation filtered at $280 \mathrm{~nm}$, (c) after $28 \mathrm{~h}$ of UV irradiation filtered at $280 \mathrm{~nm}$. Lower: The $\mathrm{CO}$ and $\mathrm{O}_{3}$ vibrational regions for $\mathrm{CH}_{3} \mathrm{Br} / \mathrm{O}_{3}$ in an argon matrix. (a) After deposition, (b) after $1 \mathrm{~h}$ of UV irradiation filtered at $280 \mathrm{~nm}$, (c) after $28 \mathrm{~h}$ of UV irradiation filtered at $280 \mathrm{~nm}$. action between argon and $O\left({ }^{1} \mathrm{D}\right){ }^{23}$ This is not the case for the $\mathrm{O}\left({ }^{3} \mathrm{P}\right)$ atom, which experiences a long range repulsive interaction with the argon lattice. ${ }^{23}$ Molecules, on the other hand, can in most cases neither rotate nor diffuse outside their original trapping site in an argon matrix at $15 \mathrm{~K}$. In this study we have therefore assumed that the singlet atomic oxygen (and to a lesser degree the triplet atomic oxygen) can move around in the matrix before reacting with the halocarbons (or $\mathrm{O}_{2}$ or $\mathrm{O}_{3}$ ). The organic reactant can not diffuse, but reaction products may dissipate their surplus energy by elbowing their way through the matrix.

The intermediates formed in the reactions $\left(\mathrm{H}_{2} \mathrm{CO}\right.$, $\mathrm{HCOBr}$ and $\mathrm{COBr}_{2}$ ) absorb in the region between 240 and $310 \mathrm{~nm}$. The UV spectrum of $\mathrm{H}_{2} \mathrm{CO}$ is well known, ${ }^{24}$ with $v_{m}$ at $310 \mathrm{~nm}$, whereas the spectra of $\mathrm{HCOBr}$ and $\mathrm{COBr}_{2}$ have not been reported. However, their $v_{\mathrm{m}}$ should be located somewhere between that of $\mathrm{COCl}_{2}$ and $\mathrm{H}_{2} \mathrm{CO}$, and $\mathrm{COCl}_{2}$ is known to have a $v_{\mathrm{m}}$ of $230 \mathrm{~nm}$. ${ }^{25} \mathrm{We}$ therefore expect photolytic decompostition of the intermediates present in our experiments when using the irradiation wavelengths reported here.

The spectral data from the matrix reaction between atomic oxygen and $\mathrm{CHBr}_{3}$ are much more complex than those from the $\mathrm{CH}_{3} \mathrm{Br}$ and $\mathrm{CBr}_{4}$ reactions. We will therefore discuss the latter results first.

$\mathrm{CH}_{3} \mathrm{Br}+\mathrm{O}$. The first set of bands appearing after irradiation (Table 5) can unambiguously be assigned to the $\mathrm{H}_{2} \mathrm{CO} \cdots \mathrm{HBr}$ complex. This complex has previously been studied in an argon matrix, and all its bands were identified. ${ }^{26}$ The complex proved very photostable under our conditions, but it eventually decomposed after extremely long irradiation to give the $\mathrm{CO} \cdots \mathrm{HBr}$ complex characterized by the 2518 and $2154 \mathrm{~cm}^{-1}$ bands. ${ }^{27,28}$ When the photolysis generated $\mathrm{O}\left({ }^{1} \mathrm{D}\right)$ the $\mathrm{CO} \cdots \mathrm{HBr}$ complex was also observed early in the experiment. The results from the $O\left({ }^{3} \mathrm{P}\right)$ experiments show that the same $\mathrm{H}_{2} \mathrm{CO} \cdots \mathrm{HBr}$ complex is formed here (although in smaller 

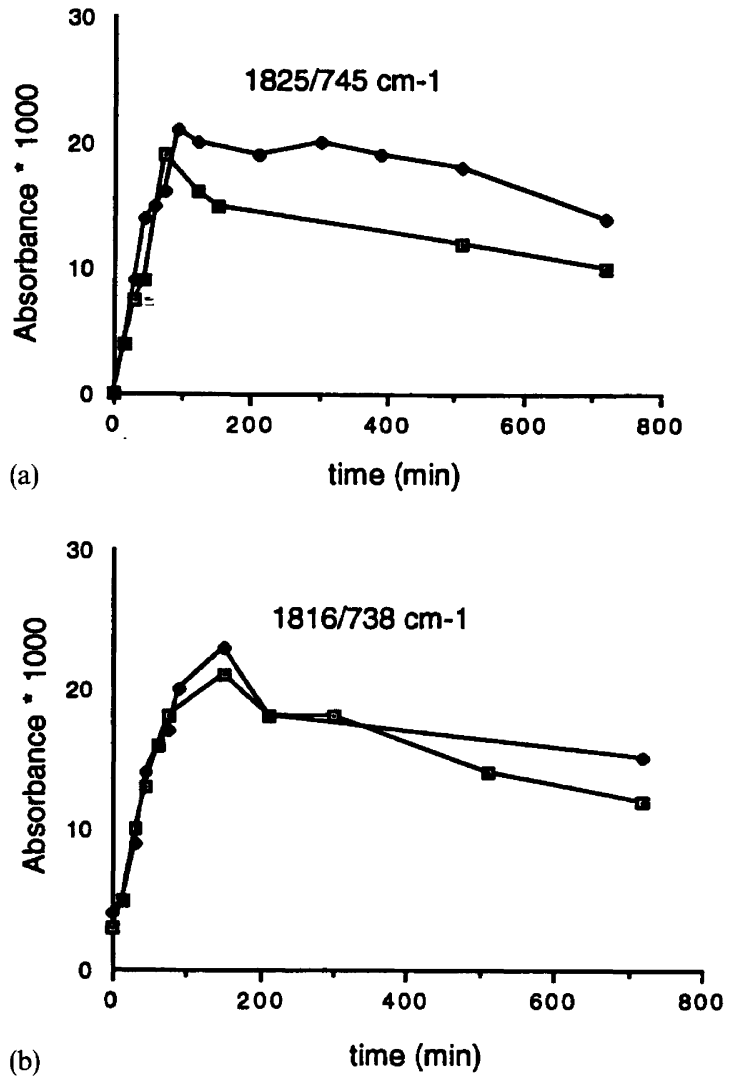

(b)

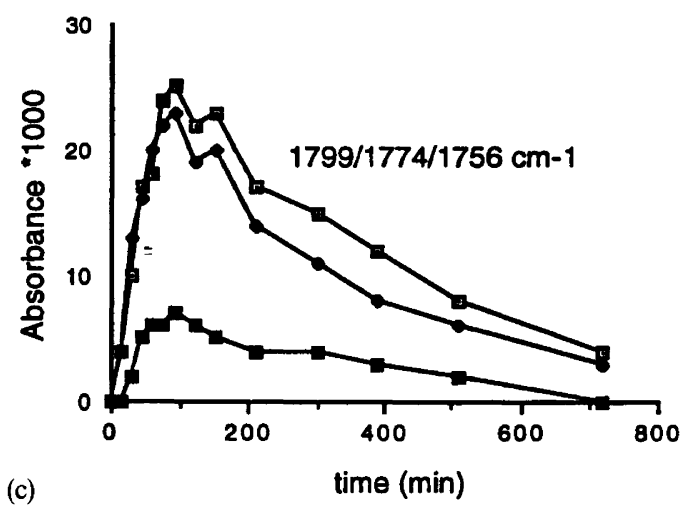

Fig. 3. Curves showing the peak intensity vs. photolysis time for the bands from the $\mathrm{CHBr}_{3} / \mathrm{O}_{3}$ experiment. (a) The 1825 and $744 \mathrm{~cm}^{-1}$ absorptions. (b) The 1816 and $737 \mathrm{~cm}^{-1}$ absorptions. (c) The 1799, 1774 and $1755 \mathrm{~cm}^{-1}$ absorptions.

quantity) and that $\mathrm{CO}$ is not formed directly in the reaction.

$\mathrm{CBr}_{4}+O$. The few IR bands appearing when $\mathrm{CBr}_{4}$ reacts with atomic oxygen are easily assigned as the possibilities for complexation are limited. In the carbonyl stretching region the $1816 \mathrm{~cm}^{-1}$ feature is assigned to free $\mathrm{COBr}_{2}$ which previously has been studied in an argon matrix. ${ }^{29}$ In addition, we also obtained authentic spectra of $\mathrm{COBr}_{2}$ for direct verification. Undoubtedly, the band at $1822 \mathrm{~cm}^{-1}$ originates from perturbed $\mathrm{COBr}_{2}$, but a blue shift of $6 \mathrm{~cm}^{-1}$ is not in accordance with a standard $n$ - $a \sigma$ complex with $\mathrm{Br}_{2}$. For comparison, the $\mathrm{C}=\mathrm{O}$ stretching mode in the $\mathrm{H}_{2} \mathrm{CO} \cdot \mathrm{Cl}_{2}$ complex is red-shifted by $10 \mathrm{~cm}^{-1} \cdot{ }^{30}$ The band could a priori be due to a dimer, but as dimers were not observed in the matrix spectra of pure $\mathrm{COBr}_{2}$ we dismiss this possibility. We are hence left with a bromine complexed or cage perturbed $\mathrm{COBr}_{2}$ as the only possibility and tentatively ascribe the $1822 \mathrm{~cm}^{-1}$ band to $\mathrm{Br}_{2} \cdots \mathrm{COBr}_{2}$. The new band in the $\mathrm{CO}$ region at $2147 \mathrm{~cm}^{-1}$, blue-shifted by $9 \mathrm{~cm}^{-1}$, is assigned to the $\mathrm{Br}_{2}$... CO complex in accordance with recent results from high-resolution IR vapour studies. ${ }^{31}$

$\mathrm{CHBr}_{3}+\mathrm{O}$. Some of the bands that appeared after irradiation of $\mathrm{CHBr}_{3} / \mathrm{O}_{3}$ in argon are easy to assign on the basis of the growth curves (Figs. $3 a-3 c$ ), the results from the $\mathrm{CBr}_{4}+\mathrm{O}$ reaction, the previous study of the $\mathrm{CH}_{2} \mathrm{Br}_{2}+\mathrm{O}$ reaction, ${ }^{9}$ and the additional information provided by using isotopes. Two of the five bands in the carbonyl region (Table 6) show no wavenumber shift when using $\mathrm{CDBr}_{3}$ as reactant but are shifted to 1783 and $1774 \mathrm{~cm}^{-1}$, respectively, when using ${ }^{18} \mathrm{O}$. Thus both of the 1825 and $1816 \mathrm{~cm}^{-1}$ bands and the corresponding bands in the $\mathrm{C}-\mathrm{Br}$ stretching region at 745 and $737 \mathrm{~cm}^{-1}$ are due to $\mathrm{COBr}_{2}$. The $1816 / 737 \mathrm{~cm}^{-1}$ pair arises from free $\mathrm{COBr}_{2}$, in agreement with the results from the $\mathrm{CBr}_{4}+\mathrm{O}$ reaction and with the previous matrix-isolation study which also reports the same isotopic shifts as here. ${ }^{29}$

The $1825 / 745 \mathrm{~cm}^{-1}$ band pair is assigned to a perturbed/complexed $\mathrm{COBr}_{2}$ in analogy to the situation described above. This interpretation relies on the reasonable assumption that $\mathrm{Br}_{2}$ can move in the matrix after being formed in a reaction which is exothermic by several hundred $\mathrm{kJ} \mathrm{mol}^{-1} .^{9}$ The alternative interpretation that the band pair originates from a $\mathrm{COBr}_{2} \cdots \mathrm{HBr}$ complex is dismissed for two reasons. (1) In other carbonyl- $\mathrm{HBr}$ complexes the carbonyl band is red-shifted by $10-20 \mathrm{~cm}^{-1}$. (2) Repeated attempts at generating a standard of this complex in the matrix failed. Only free $\mathrm{COBr}_{2}$ and free $\mathrm{HBr}$ were observed when the two compounds were co-deposited.

In the experiment with ${ }^{18} \mathrm{O}$, the $\mathrm{C}-\mathrm{Br}$ stretching region contains two band pairs at $773 / 766$ and $737 / 729 \mathrm{~cm}^{-1}$, as opposed to only one pair found in the ${ }^{16} \mathrm{O}$ and the $\mathrm{CDBr}_{3}$ experiments. The IR spectrum of $\mathrm{COBr}_{2}$ has two bands in this region: the $v_{4}$ band at $737 \mathrm{~cm}^{-1}$ and the $v_{2}+v_{5}$ combination band at $778 \mathrm{~cm}^{-1}$ enhanced by Fermi resonance. ${ }^{29}$ The reason that we only observe the combination band for $\mathrm{C}^{18} \mathrm{OBr}_{2}$ is connected with the fact that the Fermi resonance is stronger here than in $\mathrm{C}^{16} \mathrm{OBr}_{2} \cdot{ }^{29}$

The remaining bands in the carbonyl region all show wavenumber shifts when using $\mathrm{CDBr}_{3}$ and ${ }^{18} \mathrm{O}$ reactants. Hence, the bands are associated with $\mathrm{HCOBr}$ in one form or another. We follow the spectral interpretation in the matrix isolation study of the $\mathrm{O}+\mathrm{CH}_{2} \mathrm{Br}_{2}$ reaction, ${ }^{9}$ where the band at $1799 \mathrm{~cm}^{-1}$ was assigned to the $v_{2}$ mode of free $\mathrm{HCOBr}$ and the $1756 \mathrm{~cm}^{-1}$ band to the $\mathrm{CHOBr} \cdots \mathrm{HBr}$ complex. The latter interpretation 
requires that also $\mathrm{HBr}$ is mobile in the matrix just after being formed, but the isotopic shifts for these bands (Table 6) are identical to those observed in Ref. 9, where $\mathrm{HCOBr}$ and $\mathrm{HBr}$ are formed in the same matrix cage and further consistent with the shift reported in the gas phase for DCOBr. ${ }^{32}$ The $v_{2}$ mode of free $\mathrm{HCOBr}$ is in Fermi resonance with the $2 v_{6}$ mode at $1772 \mathrm{~cm}^{-1}$, which in the present experiment is partly overlapped by a stronger band at $1774 \mathrm{~cm}^{-1}$. Finally the 1774, 1737 $\left({ }^{18} \mathrm{O}\right)$, and 1739 (D) $\mathrm{cm}^{-1}$ bands, which were not observed in the similar experiments with methyl bromide, methylene bromide, ${ }^{9}$ or cabon tetrabromide, are tentatively assigned to the $\mathrm{HCOBr} \cdots \mathrm{Br}_{2}$ complex.

The complex structures in $\mathrm{HBr}$ and $\mathrm{CO}$ regions are not completely assigned, and the experiments with deuterated or ${ }^{18} \mathrm{O}$ isotopes are of little help. As previously mentioned, the band around $2518 \mathrm{~cm}^{-1}$ stems from the $1: 1$ complex of $\mathrm{CO} \cdots \mathrm{HBr}{ }^{26,27}$ The corresponding CO band is found at $2154 \mathrm{~cm}^{-1}$. The bands at 2498 and $2488 \mathrm{~cm}^{-1}$ are due to the $2: 1$ complex of $\mathrm{HBr}$ and CO. ${ }^{9,27,28}$ After prolonged photolysis a number of absorptions appear in the spectra between 2518 and $2498 \mathrm{~cm}^{-1}$ (Table 7). We suggest that the 2506 and
$2502 \mathrm{~cm}^{-1}$ bands may be due to self-association of $\mathrm{HBr}$, or $\mathrm{HBr}$ complexed with water which is always present in trace amounts.

The most prominent features in the $\mathrm{CO}$ spectral reagion are found at 2154 and $2138 \mathrm{~cm}^{-1}$, corresponding to $\mathrm{CO}$ complexed to $\mathrm{HBr}$ and free $\mathrm{CO}$, respectively. The $\mathrm{CO}$ stretching vibrations in the $\mathrm{CO} \cdots \mathrm{HBr}$ and $\mathrm{CO} \cdots \mathrm{HBr} \cdots \mathrm{HBr}$ complexes are very close, and they can not be separated when the bands are somewhat broadened as here. There are a number of lines between these two features. One of them at ca. $2147 \mathrm{~cm}^{-1}$ is most likely due to the $\mathrm{CO} \cdots \mathrm{Br}_{2}$ complex which was also observed in the $\mathrm{CBr}_{4} / \mathrm{O}_{3}$ experiment.

Mechanism. The experimets show that there are two mechanistic pathways in the reaction of $\mathrm{CH}_{3} \mathrm{Br}$ with $\mathrm{O}\left({ }^{1} \mathrm{D}\right)$ : (i) the formation of $\mathrm{H}_{2} \mathrm{CO}$ and $\mathrm{HBr}$ followed by photodecomposition to $\mathrm{H}_{2}, \mathrm{HBr}$ and $\mathrm{CO}$ after prolonged irradiation; and (ii) direct formation of $\mathrm{CO}$ and $\mathrm{HBr}$. With $\mathrm{O}\left({ }^{3} \mathrm{P}\right)$ only route (i) seems possible (Fig. 4$)$.

Similarly, the $\mathrm{CBr}_{4} / \mathrm{O}$ experiments show that the $\mathrm{O}\left({ }^{1} \mathrm{D}\right)$ reaction has two paths: One leading to $\mathrm{COBr}_{2}$ and $\mathrm{Br}_{2}$ followed by photodecomposition to $\mathrm{CO}$ and $\mathrm{Br}_{2}$, the

Table 6. Intermediate product bands (in $\mathrm{cm}^{-1}$ ) from the $\mathrm{CHBr}_{3}+\mathrm{O}\left({ }^{1} \mathrm{D}\right.$ ) experiments.

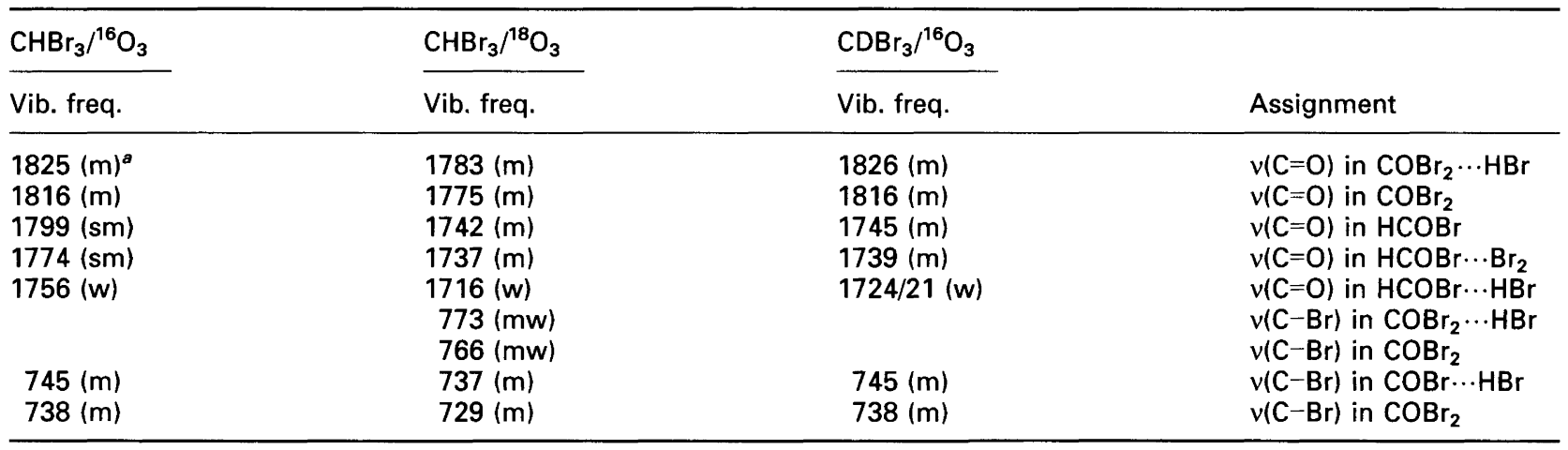

${ }^{a}$ Abbreviations: s, strong; m, medium; w, weak.

Table 7. Final product bands (in $\mathrm{cm}^{-1}$ ) from the $\mathrm{CHBr}_{3}+\mathrm{O}\left({ }^{1} \mathrm{D}\right.$ ) experiments.

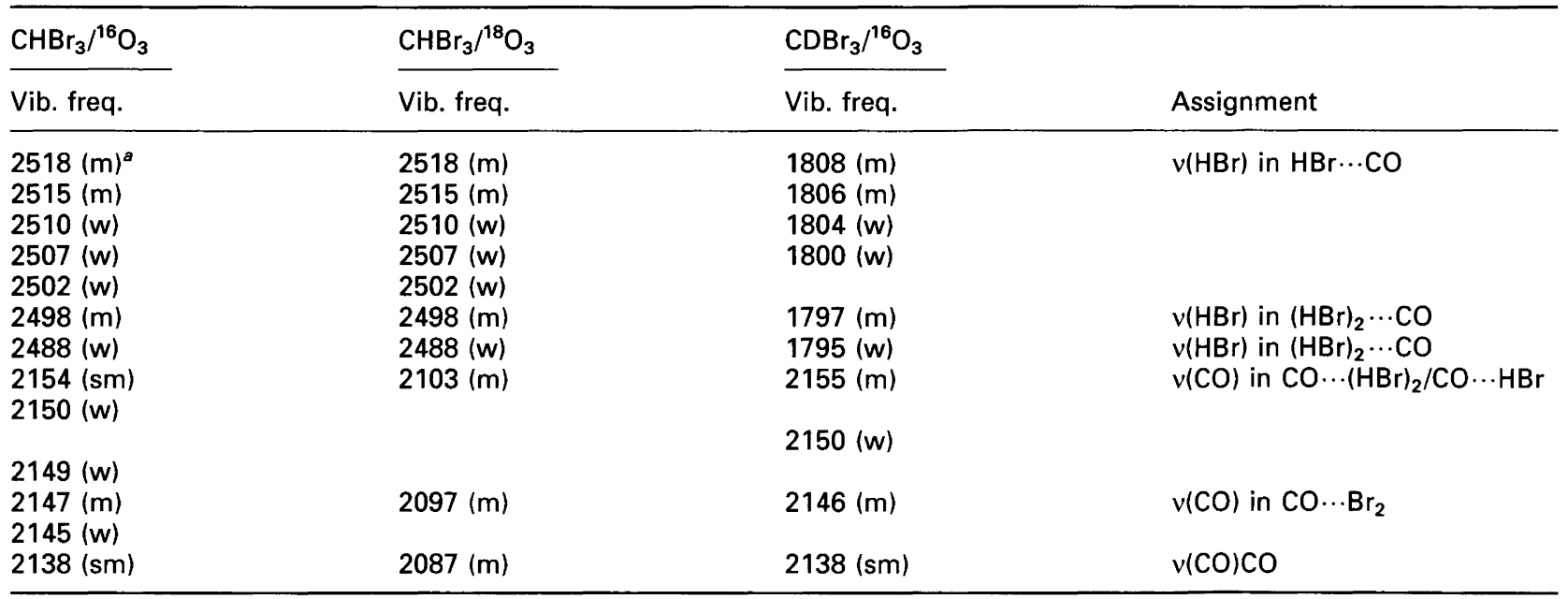

${ }^{a}$ Abbreviations: s, strong; m, medium; w, weak. 

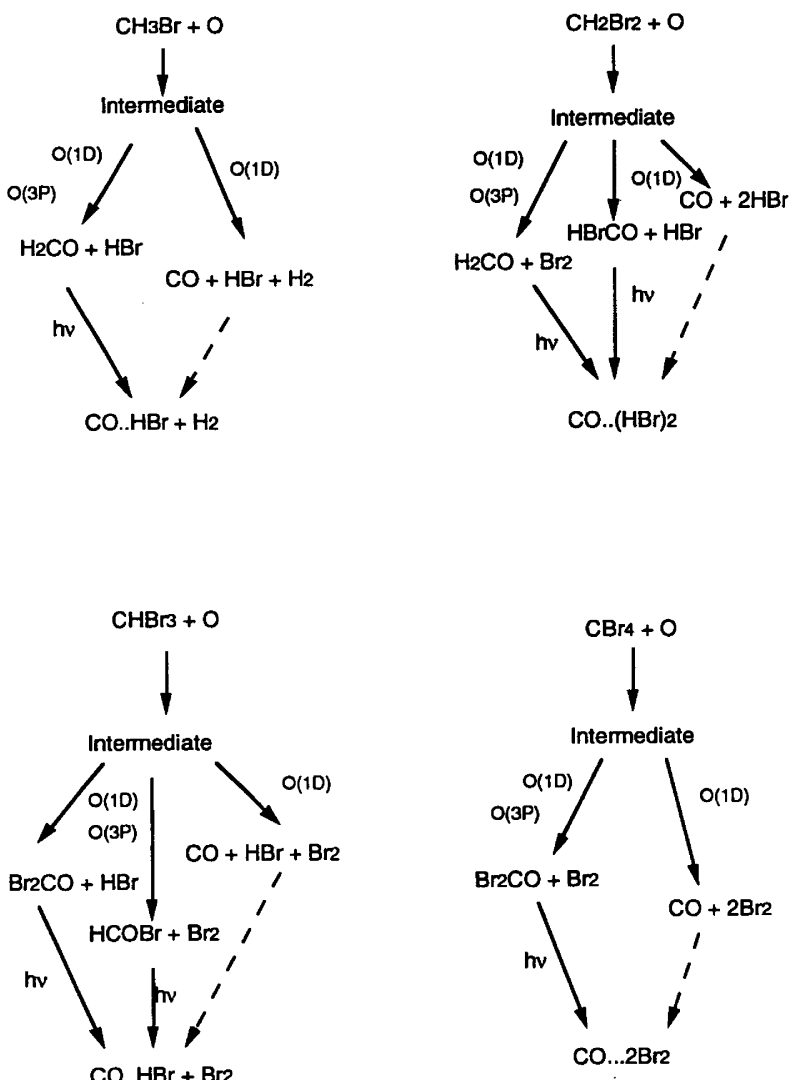

Fig. 4. Proposed pathways for the reaction between bromomethanes and atomic oxygen.

other leading direct to $\mathrm{CO}$ and $\mathrm{Br}_{2}$. For the $\mathrm{O}\left({ }^{3} \mathrm{P}\right)$ reaction only the first path seems possible (Fig. 4).

For the $\mathrm{CHBr}_{3}+\mathrm{O}$ reaction there seemed to be three routes to the final products for $\mathrm{O}\left({ }^{1} \mathrm{D}\right)$ : (i) formation of $\mathrm{COBr}_{2}$ and $\mathrm{HBr}$ followed by decomposition to $\mathrm{CO}, \mathrm{Br}_{2}$ and $\mathrm{HBr}$ upon further photolysis; (ii) formation of $\mathrm{HCOBr}$ and $\mathrm{Br}_{2}$ followed by a similar decomposition upon photolysis; and (iii) direct formation of $\mathrm{CO}$ and $\mathrm{HBr}$. With $\mathrm{O}\left({ }^{3} \mathrm{P}\right)$ only paths (i) and (ii) were observed Fig. 4.

The question of how the oxygen atom initially attacks the halocarbons still remains. The primary step for the oxygen attack can be one of the following: the atomic oxygen may (i) insert into a $\mathrm{CH}$ bond, (ii) insert into a $\mathrm{CBr}$ bond, (iii) abstract a hydrogen or halogen atom, or (iv) add to the carbon forming a five-coordinated, excited intermediate. Previous studies of $O\left({ }^{1} \mathrm{D}\right)$ insertion versus abstraction for hydrocarbons reacting indicate that the insertion mechanism dominates for the small hydrocarbons. ${ }^{33,34}$ Insertion can also occur with the $\mathrm{O}\left({ }^{3} \mathrm{P}\right)$. Literature data ${ }^{35}$ show that hydrogen or halogen atom abstraction is thermodynamically favourable with $\mathrm{O}\left({ }^{1} \mathrm{D}\right)$, while the reaction is endothermic with $\mathrm{O}\left({ }^{3} \mathrm{P}\right)$. The spectroscopic evidence obtained in this study can not conclusively indicate the initial step of these reactions.

Acknowledgement. We thank Profs. P. Klæboe and L. Schriver-Mazzuoli for helpfull discussions. Financial support from The Nansen Foundation and the Elf Aquitaine UiO support programme is acknowledged.

\section{References}

1. Lovelock, J. E., Maggs, R. J. and Wade, R. J. Nature (London) 241 (1973) 194.

2. Molina, M. J. and Rowland, F. S. Nature (London) 249 (1974) 810.

3. Wofsey, S. C., McElroy, M. B. and Yung, Y. L. Geo. Res. Lett. 2 (1975) 215.

4. Yung, Y. L., Pinto, J. P., Watson, R. T. and Sander, S. P. J. Atmos. Sci. 37 (1980) 339.

5. Weller, R., Lorentzen-Schmidt, H. and Schrems, O. Ber. Bunsenges. Phys. Chem 96 (1992) 409.

6. Abedelaoui, O., Schriver, L. and Schriver, A. J. Mol. Struct. 268 (1992) 335.

7. Schriver, L., Gauthier-Roy, B., Carrer, D., Schriver, A. and Abouaf-Marguin, L. A. Chem. Phys. 163 (1992) 357.

8. Schriver, L., Abedelaoui O. and Schriver, A. J. Phys. Chem. 96 (1992) 8069.

9. Lugez, C., Lasson, E., Nielsen, C. J., Schriver A. and Schriver-Mazzuoli, L. J. Phys. Chem. 97 (1993) 11619.

10. Lasson, E., Klaeboe, P. and Nielsen, C. J. Air Pollution Res. Rep. 42 (1991) 79.

11. Baulch, D. L., Cox, R. A., Hampson, R. F., Kerr, J. A., Troe, J. and Watson, R. T. J. Phys. Chem. Ref. Data 9 (1980) 295.

12. McCaa, D. J. and Shaw, J. H. J. Mol. Spectrosc. 25 (1968) 374.

13. Andrews, L. and Spiker, R. C. J. Chem. Phys. 22 (1972) 3208.

14. Jones, E. W., Poppelwell, R. J. L. and Thompson, H. W. Spectrochim. Acta 22 (1966) 647.

15. Barnes, A. J., Hallam, H. E., Howells, J. D. R. and Scrimshaw, G. F. J. Chem. Soc., Faraday Trans. 69 (1973) 738.

16. Bruger, H. and Cichon, J. Spectrochim. Acta, Part A 27 (1971) 2191.

17. Carver, T. G. and Andrews, L. J. Chem. Phys. 50 (1969) 4223.

18. Meister, A. G., Rosser, S. E. and Cleveland, F. F. J. Chem. Phys. 18 (1950) 346.

19. Rogers, E. E., Abramowitz, S., Jacox, M. E. and Milligan, D. E. J. Chem. Phys. 52 (1970) 2198.

20. Fournier, J., Mohammed, H. H., Deson, J. and Millard, D. Chem. Phys. 70 (1982) 39.

21. Millard, D., Fournier, J., Mohammed, H. H. and Girardet, C. J. Chem. Phys. 78 (1983) 5480.

22. Mohammed, H. H. J. Chem. Phys. 93 (1990) 412.

23. Benderskii, A. V. and Wight, C. A. J. Chem. Phys. 101 (1994) 292.

24. Clavert, J. G. and Pitts Jr, J. N. Photochemistry, Wiley, New York 1966.

25. Moule, O. C. and Foo, P. D. J. Chem. Phys. 55 (1971) 1262.

26. Nelander, B. J. Mol. Struct. 69 (1980) 59.

27. Barnes, A. J., Hallam, H. E. and Scrimshaw, G. F. Trans. Faraday Soc. 65 (1969) 3172.

28. Andrews, L., Arlinghaus, R. T. and Johnson, G. L. J. Chem. Phys. 78 (1983) 6347.

29. Hauswirth, W. and Willner, H. Spectrochim. Acta 35 (1979) 271.

30. Strandman-Long, L., Nelander B. and Nord, L. J. Mol. Struct. 117 (1984) 217.

31. Lin, Y. and Beaudet, R. J. Phys. Chem. 98 (1994) 8310.

32. Yarwood, G., Niki, H. and Maker, P. D. J. Phys. Chem. 95 (1991) 4773.

33. Luntz, A. C. J. Chem. Phys. 73 (1980) 1143.

34. Nakajinia, M., Tsuda, M. and Oikawa, S. Chem. Pharm. Bull. 35 (1987) 941.

35. Baulch, D. L., Cox, R. A., Crutzen, P. J., Hampson Jr., R. F., Kerr, J. A., Troe, J. and Watson, R. T. J. Phys. Chem. Ref. Data, 11 (1982) 327.

Received June 2, 1995. 